\title{
FORMAÇÃO CONTINUADA DE PROFESSORES: UMA PESQUISA COLABORATIVA COM PROFESORES-ENGENHEIROS
}

\author{
DOI: 10.37702/2175-957X.COBENGE.2021.3686
}

Terezinha Severino da Silva - terezinha.silva@uftm.edu.br Universidade Federal do Triângulo Mineiro

Rua Dr Mário de Almeida Franco 1069

38046-320 - Iturama - MG

Resumo: Resumo: Esse artigo apresenta parte de uma pesquisa colaborativa intitulada "Formação continuada de professores-engenheiros: uma pesquisa colaborativa", desenvolvida com docentes dos cursos de engenharia do Instituto de Ciências Tecnológicas e Exatas (ICTE) da Universidade Federal do Triângulo Mineiro - UFTM, visando contribuir para o seu desenvolvimento profissional. A pesquisa baseou-se na abordagem qualitativa, tendo como método o Materialismo Histórico-Dialético. O recorte escolhido para esse artigo refere-se à descrição da pesquisa colaborativa utilizada por ter a expectativa de que o conhecimento fosse construído por meio da interação dos sujeitos - participantes e pesquisadora, buscando a reflexão sobre os significados de suas próprias ações. A pesquisa colaborativa, por meio das atividades presenciais e a distância, nos grupos de reflexões, pôde contribuir para a apreensão de saberes e puderam auxiliar o professor a valorizar o pensamento do outro, propiciando ambientes de discussão, de autonomia e de respeito mútuo e os mesmos compreenderam que o desenvolvimento da reflexão é necessário, o que pode promover mudança em sua prática docente.

Palavras-chave: Formação de professores. Pesquisa colaborativa. Desenvolvimento profissional docente. 


\section{FORMAÇÃO CONTINUADA DE PROFESSORES: UMA PESQUISA COLABORATIVA COM PROFESORES-ENGENHEIROS}

\section{Introdução}

O presente artigo tem como objetivo apresentar parte de uma pesquisa que se desenvolveu na forma de uma pesquisa colaborativa com professores que ministram aulas na formação básica comum dos cursos de engenharia do ICTE/UFTM. A proposta foi de uma pesquisa colaborativa, apoiada nas premissas de Ibiapina (2008; 2016), contemplando as seguintes fases ou etapas: 1) Sensibilização dos colaboradores; 2) Negociação dos espaços e tempos; 3) Diagnóstico das necessidades formativas e dos conhecimentos prévios; 4) Sessões de estudo, intercaladas pelos ciclos reflexão interpessoal e intrapessoal, e 5) Análises das práticas docentes.

Todas as ações desenvolvidas são interdependentes, num movimento contínuo, o que se torna difícil de ser mostrado e percebido num fluxograma. A etapa de sensibilização foi realizada em dois momentos: um primeiro momento, individualmente, em entrevista com o professor e, posteriormente, no primeiro encontro de formação com todo o grupo, de forma coletiva.

O diagnóstico das necessidades de formação foi feito por meio de entrevista semiestruturada, realizada no final de 2018 e início do ano de 2019. Os docentes foram entrevistados com questões sobre sua formação, importância dada à formação pedagógica, à motivação para participar de uma formação e aos tópicos primordiais para a formação do professor das engenharias. Foram discutidas as temáticas convergentes entre os docentes, no primeiro encontro da formação, no qual ficaram definidos os temas a serem abordados.

As sessões de estudo e a análise das práticas docentes, intercaladas pelos ciclos de reflexão interpessoal e intrapessoal, ocorreram ao longo de todo o processo, com utilização de metodologias ativas, dinâmicas de grupos, e outras estratégias utilizadas de forma colaborativa.

Foram realizados seis encontros presenciais, chamados por lbiapina (2008) de ciclos reflexivos e quatro atividades a distância, conforme planejamento dos participantes e pesquisadora e, como a pesquisa teve abordagem colaborativa, as etapas foram sendo avaliadas na medida em que a formação ia acontecendo.

O fluxograma, descrito na Figura 1, demonstra o plano da pesquisa colaborativa. 


\section{COBENCE e IV Simpósio Internacional de Educaçăo em Engenharia 2021 da ABENGE \\ 28 a 30 de SETEMBRO \\ Evento Online \\ Formação em Engenharia: \\ Tecnologia, Inovação e Sustentabilidade"}

Figura 1- Fluxograma da proposta de pesquisa colaborativa com docentes do ICTE/UFTM

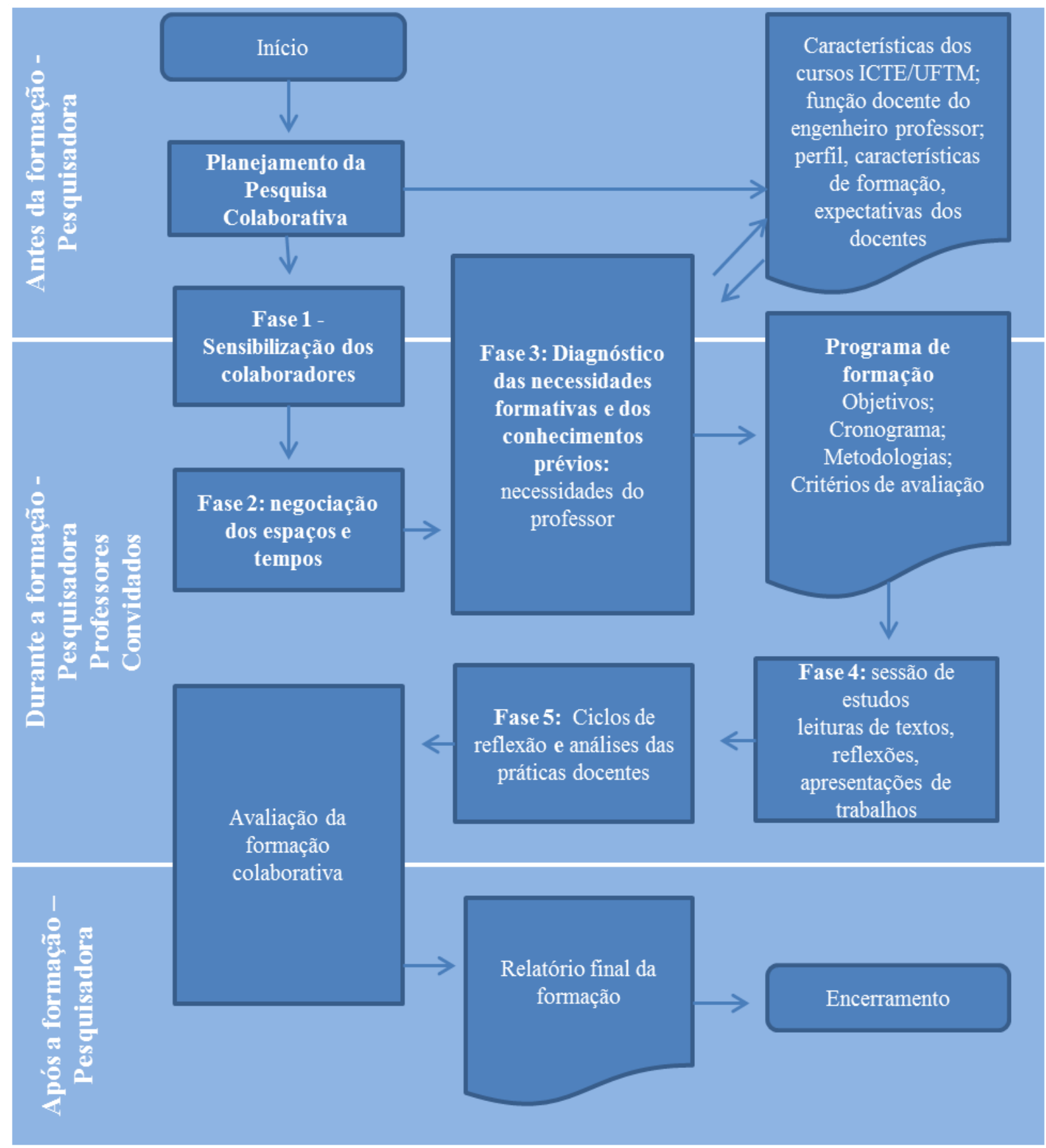

Fonte: Elaborado pela autora a partir de Ibiapina (2008).

A conclusão da formação deu-se com a avaliação, envolvendo a autoavaliação de todos os participantes e avaliação da formação como um todo. 


\section{A pesquisa colaborativa- fundamentos teóricos}

Foi utilizada a pesquisa colaborativa pela preocupação com o universo de problemas que a docência e a formação de professores enfrentam numa relação que existe entre a educação e a sociedade, no sentido de melhorar ou de modificar a compreensão dessa temática e da prática docente. Trata-se, portanto, da coparticipação do docente e do pesquisador, em todo o processo. Esse tipo de pesquisa visa à ressignificação da prática do docente em sala de aula, pelos participantes, auxiliados pelos seus pares que têm mais experiência, proporcionando a interação de todos os envolvidos na pesquisa, "calcados em decisões e análises construídas por meio de negociações coletivas, tornam-se co-parceiros, co-usuários e co-autores de processos investigativos delineados a partir da participação ativa, consciente e deliberada" (IBIAPINA, 2008, p. 26).

A pesquisa colaborativa caracteriza-se pela busca do desenvolvimento profissional na reflexão e busca por soluções para suas demandas e problematização da sua formação e prática, visando atender suas reais necessidades de formação e, ainda, contribuindo para um novo conhecimento científico.

Desgagné (2007) traz a descrição das bases conceituais da abordagem colaborativa de pesquisa em educação, que reúne pesquisador e docente tratando de questões relacionadas ao seu exercício profissional. São três, de acordo com o autor, as bases conceituais:

A abordagem colaborativa supõe um processo de co-construção entre parceiros envolvidos; joga simultaneamente sobre dois registros, que é o da produção de conhecimentos e o do desenvolvimento profissional dos docentes e; contribui para a aproximação e mediação entre comunidade de pesquisa e escolar. (DESGAGNÉ, 2007, p. 7).

A pesquisa colaborativa favorece as relações entre os sujeitos envolvidos. Na perspectiva da teoria histórico-cultural, os sujeitos se constituem nas relações sociais, em processos, inicialmente, interpsicológicos, e, depois intrapsicológicos. Para tanto, nesse tipo de pesquisa, o pesquisador deve criar condições para que os professores pactuem com ele no processo de reflexão sobre a docência, respondendo, assim, às suas necessidades de desenvolvimento profissional.

Ibiapina considera pertinente esse tipo de pesquisa no ambiente escolar:

[...] quando o pesquisador aproxima suas preocupações das preocupações dos 
professores, compreendendo-as por meio da reflexividade crítica, e proporciona condições para que os professores revejam conceitos e práticas; e de outro lado, contempla o campo da prática, quando o pesquisador solicita a colaboração dos docentes para investigar certo objeto de pesquisa, investigando e fazendo avançar a formação docente, esse é um dos desafios colaborativos, responder as necessidades de docentes e os interesses de produção de conhecimentos. A pesquisa colaborativa, portanto, reconcilia duas dimensões da pesquisa em educação, a produção de saberes e a formação continuada de professores. Essa dupla dimensão privilegia pesquisa e formação, fazendo avançar os conhecimentos produzidos na academia e na escola. (IBIAPINA, 2008, p. 114-115, grifos nossos).

A autora concebe a pesquisa colaborativa como uma construção de conhecimento baseada na reflexão e que se desenvolve pelas relações e articulações que são "negociadas" entre os participantes, considerando suas necessidades. Assim, a pesquisa deve seguir na direção dialética da realidade social, num movimento histórico, nos confrontos entre teoria e prática, para que os professores possam compreender, analisar e produzir conhecimentos que podem mudar a realidade. Assim, para que um trabalho colaborativo seja efetivo, é muito importante considerar a relação entre a teoria e a prática, no sentido dialético, de unidade de contrários, bem como o contexto e seus participantes.

De acordo com Santos e Magalhães (2016), a pesquisa colaborativa:

Viabiliza a vivência de ZDP ${ }^{1}$ (Zona de Desenvolvimento Proximal) compreendida como um espaço de ação criativa, pautadas na compreensão e transformação por parte dos participantes, decorrentes dos sentidos dados aos conceitos trabalhados com foco no objeto, estes mediados pelas regras, papéis dos sujeitos e divisão do trabalho, permitindo aos mesmos, novas formas de agir e se relacionar. (SANTOS; MAGALHÃES, 2016, p. 181).

Esse conceito de ZDP, proposto por Vigotski (1998), é basilar quando se trata de ensino e aprendizagem. Num processo formativo de professores, há a apropriação de conceitos, formas de agir, que conduzem os participantes de um nível de desenvolvimento real para um nível de desenvolvimento potencial. O que importa é prática que transforma a realidade, tanto no plano do conhecimento quanto no plano histórico social, sustentando o conhecimento "na e pela" práxis.

\section{O caminho da pesquisa colaborativa}

1 [ZDP] é a distância entre o nível de desenvolvimento real, que se costuma determinar através da solução independente de problemas, e o nível de desenvolvimento potencial, determinado através da solução de problemas sob a orientação de um adulto ou em colaboração com companheiros mais capazes (VIGOTSKI, 1991, p. 97) 
A presente pesquisa caracterizou-se pela busca do desenvolvimento profissional na reflexão dos docentes que participaram e pela busca por soluções para suas demandas e problematização da sua formação e prática, visando atender suas reais necessidades de formação e, ainda, contribuindo para um novo conhecimento científico. Esse conhecimento científico pressupõe aprendizagem, aprendizagem sobre sua prática docente, possível quando parte de desejo de mudança, de interesse, não só numa dimensão cognitiva, como também afetiva.

Foram realizados seis encontros presenciais e quatro atividades a distância, de agosto a novembro de 2019. As atividades a distância foram desenvolvidas por meio da plataforma Google Classroom, em dias e horários combinados com os participantes. Com as atividades presenciais e a distância, buscamos a apropriação de conhecimentos científico-pedagógicos e de novos sentidos e significados para o ensino-aprendizagem, visando contribuir para o desenvolvimento profissional do docente.

$1 \%$ encontro presencial: $O$ objetivo do encontro era estudar com os participantes os pressupostos metodológicos da pesquisa colaborativa e planejar a formação continuada. Era fundamental que os participantes compreendessem a pesquisa colaborativa como uma importante estratégia de investigação, que visa refletir sobre a prática docente envolvida. Nesse encontro, foram apresentados os resultados da primeira entrevista realizada no final de 2018 e início do ano de 2019. O encontro foi finalizado com o planejamento geral das atividades presenciais e a distância.

1a atividade a distância: A proposta da atividade foi fazer a leitura de uma carta remetida a Fábio Schvartsman: Schvartsman, você está errado, publicado no jornal Folha de São Paulo, no dia 25/02/2019 - A3 - na seção Tendências/Debate, em que Patrícia Borelli - filha de uma desaparecida na tragédia de Brumadinho - MG, rebate a fala do presidente da Vale Brumadinho de que a empresa é uma "joia" e que não podia ser condenada por um acidente, por maior que tenha sido a tragédia. Considerando que, em menos de três anos, ocorreram diversas catástrofes ambientais, a atividade foi a proposta de um diálogo online sobre o que esses eventos têm a ver com a profissão do engenheiro e que implicações isso traz para a sua formação.

O objetivo dessa discussão era refletir sobre a responsabilidade do professor para a formação de um engenheiro com competências e habilidades para o exercício de sua profissão, consciente das implicações sociais, ecológicas e éticas que envolvem sua atuação. Os professores demonstraram preocupação com a formação ética do aluno do ICTE, porém, acreditam que com bons exemplos o processo de formação do aluno pode ter êxito. Nos indicadores inferidos estão presentes as contradições: o componente ético é importante, mas não atravessa a prática pedagógica em toda a sua dimensão. 
2 Encontro presencial: estratégias de ensino: Para esse encontro, convidamos um professor do Instituto Federal do Triângulo Mineiro (IFTM), profissional conhecedor de metodologias ativas e três professores do ICTE que utilizaram de metodologias ativas em suas aulas, ao longo do semestre, para compartilhar com o grupo suas experiências. A apresentação do professor foi feita em duas horas e o mesmo se dispôs em responder a dúvidas e questionamentos que porventura fossem tendo, ao longo da apresentação. Em forma de seminário, o professor apresentou algumas metodologias ativas: I- Método 300; II- Mapa Conceitual; III- Aula invertida e IV- Problem Basead Learning (PBL)

Para que fosse exercida a autonomia dos participantes da pesquisa, cada professor escolheu a estratégia mais adequada ao conteúdo de sua disciplina. Essa estratégia foi aplicada em uma de suas aulas seguintes. Sabe-se que não é suficiente usar essa ou aquela estratégia de ensino, como garantia de aprendizagem e de desenvolvimento do aluno, pois, nem todas as estratégias atendem a todos os tipos de alunos e, ainda, elas podem ter limitações, por diversos fatores, como a idade, o nível de conhecimento do aluno, porém, podem subsidiar o trabalho do professor no processo de ensino-aprendizagem.

Para fazer o planejamento da aula ou das aulas necessárias para aplicação da estratégia, utilizamo-nos de um texto norteador - Planejamento Escolar, de Libâneo (1994). A leitura do texto e a tarefa de fazer o planejamento compuseram a $2^{2}$ atividade a distância da formação.

2ª Atividade a distância: Planejamento Escolar: A $2^{\underline{a}}$ atividade a distância foi a leitura do texto de Libâneo (1994) O Planejamento Escolar e da elaboração de um plano de aula, considerando a estratégia de ensino escolhida no $2^{0}$ encontro da formação. Os professores manifestaram a importância de um texto norteador para a elaboração do seu plano de aula e consideraram-no como um processo de "racionalização, organização e coordenação da ação docente, articulando a atividade escolar e a problemática do contexto social", como bem disse Libâneo (1994). Consideraram importante fazer a articulação do assunto com o contexto em que o aluno e professor estão inseridos, tornando o processo mais participativo; relacionando os objetivos, conteúdos, métodos e formas de organizarem o ensino, bem como a forma de avaliar de forma pertinente o tema (conteúdo) discutido; e, ainda, utilizando-se de uma estratégia de ensino diferente das que, rotineiramente, utilizavam, o que os deixaram de certa forma, apreensivos, porém, confiantes de que uma forma diferente de abordar/trabalhar/discutir os assuntos trariam diferentes aprendizagens.

3를 Encontro presencial: estratégias de ensino - relato de experiências: $O$ objetivo desse 
encontro foi relatar a experiência vivenciada com o uso da estratégia de ensino escolhida pelo professor no segundo encontro. De acordo com as DCN para os cursos de engenharia, é necessária a adoção de medidas para a formação de um engenheiro que atenda às demandas de um profissional com competências técnicas para o mercado de trabalho, como:

[...] adotar as metodologias de ensino mais modernas e mais adequadas à nova realidade global, as que se baseiam na vasta utilização de tecnologias da informação e atuam diretamente na vertente mobilidade urbana, aliada ao desenvolvimento de competências comportamentais e à motivação dos estudantes para buscar fontes diversas de conteúdo. (CNE, 2019, p._29).

O uso dessas metodologias pode promover maior sentido e dinamismo no processo de ensino-aprendizagem, contribuindo para a melhoria do ensino e a diminuição da evasão e retenção dos estudantes nesses cursos.

\begin{abstract}
Para se envolver ativamente no processo de aprendizagem, o aluno deve ler, escrever, perguntar, discutir ou estar ocupado em resolver problemas e desenvolver projetos. Além disso, o aluno deve realizar tarefas mentais de alto nível, como análise, síntese e avaliação. Nesse sentido, as estratégias que promovem aprendizagem ativa podem ser definidas como sendo atividades que ocupam o aluno em fazer alguma coisa e, ao mesmo tempo, o leva a pensar sobre as coisas que está fazendo. (BARBOSA; MOURA, 2014, p. 2).
\end{abstract}

Essas estratégias podem subsidiar uma pedagogia mais dinâmica, centrada na atividade do aluno, com perspectiva de construção do conhecimento, do seu protagonismo e autonomia, contribuindo para a formação de profissionais mais críticos, mais criativos, capazes de propor soluções para os problemas da sociedade atual.

Nesse processo de formação da atividade de estudo, o papel do professor é primordial, pois é ele quem organiza as tarefas de estudo e auxilia o seu aluno a compreender e a realizar as ações de estudo, controle e avaliação dessa tarefa. Dessa maneira, o professor cria situações que proporcionam ao aluno a autonomia na resolução das tarefas de estudo e a formação da capacidade de estudar.

\title{
4 Encontro presencial: Avaliação do processo ensino-aprendizagem no ensino superior: $O$
} objetivo foi discutir a avaliação do processo de ensino-aprendizagem na educação superior. A discussão iniciou-se a partir da leitura de cartazes com conceitos de avaliação de diversos autores 
que estudam a avaliação, trazidos pelas convidadas. No formato de círculo, os participantes e convidadas debateram o tema.

Para fundamentar a discussão, foi feita a leitura do texto: Uma visão panorâmica das atuais práticas pedagógicas e avaliativas no ensino superior, que aborda a avaliação do processo ensinoaprendizagem na educação superior, na visão de autores que pesquisam a temática, delineando valores, concepções e sentidos para a avaliação. Para esses autores, as práticas avaliativas nas instituições, principalmente as de educação superior, são vistas como excludentes quando praticadas de forma autoritária e discriminatória. E tão quão importante é averiguar o motivo de não se alcançarem esses objetivos, ou seja, conhecer os impedimentos que provocaram o desvio de metas estabelecidas para o alcance deles.

Inicialmente visto como um mecanismo de verificação das competências desenvolvidas pelo aluno durante e ao final do processo de ensino-aprendizagem. Este tema é revelador da competência do professor (ensino) e do compromisso e adequação da proposta (planejamento de ensino) ao projeto pedagógico do aluno (aprendizagem). [...] Portanto avaliar não é mensurar valores e também não significa medir competências, mas sim verificar o caminho percorrido pelo aluno ao longo do processo de aprendizagem. (VITO; SZEZERBATZ, 2017, p. 225).

As autoras consideram que a avaliação não pode ser tratada como algo estanque, mas como parte de um processo que está para além de momentos eventuais, como a prova, por exemplo, de um determinado conteúdo e/ou em testes específicos e padronizados que caracterizam um aluno/pessoa pelo seu nível de compreensão de um conceito, não devendo ser, pois, sinônimo de julgamento e nem mensuração de valores.

No final do encontro, foi proposto que cada professor pensasse em um instrumento de avaliação, diferente do que tem usado para que fosse utilizado em, pelo menos, uma de suas turmas. A experiência do uso desse "novo" instrumento foi apresentada no próximo encontro presencial, que ocorreu no dia 7 de novembro de 2019, de acordo com o planejamento.

\section{5o Encontro presencial: Avaliação do processo ensino-aprendizagem - relato de}

experiências: $O$ uso do instrumento avaliativo escolhido por eles no $4^{\circ}$ encontro, considerando que o instrumento de avaliação funciona como um elemento que integra o processo de ensinoaprendizagem, o que denota a compreensão do professor sobre a importância do ato de avaliar. A partir das falas dos participantes nesse encontro podemos perceber que a avaliação é um dos maiores desafios em todo o processo de ensino-aprendizagem. Porém, os indicadores de significados revelam a presença de contradições, no sentido de que a avaliação é importante, devemos variar as formas e os instrumentos, mas é difícil se ser concretizada - "se o aluno aprende 
está pronto para qualquer tipo de prova".

Os relatos de experiência com o uso de um instrumento avaliativo diferente dos que utilizam representou mais que uma avaliação, proporcionou uma oportunidade de aprendizagem.

\section{3ª Atividade a distância: Elaboração de Mapa Conceitual - tema - avaliação educacional: A} atividade constituiu-se da leitura do texto: O lugar da avaliação da aprendizagem no território da pedagogia universitária para a elaboração de um mapa conceitual. O objetivo da atividade de elaboração do mapa conceitual era proporcionar aos participantes da pesquisa a oportunidade de utilizar-se de um recurso de aprendizagem para a apreensão da visão geral do tema avaliação do processo de ensino-aprendizagem, no contexto da educação superior, em forma de conexão das ideias colocadas no texto.

Para Veiga (2013), não há uma única forma de representar um conceito, pois cada autor tem uma forma de perceber ou representá-la e define o mapa conceitual:

O mapa conceitual, por excelência, é um ato metodológico centrado na representação cognitiva e gráfica sobre o conhecimento, tendo como foco a consciência pedagógica, a curiosidade, as descobertas, as dúvidas, as mudanças, as inovações com ênfase na reflexão sobre a reflexão por meio da visualização e da escrita. Ao representar graficamente um conteúdo/conhecimento com significado, a análise poderá ser feita de forma contextualizada a fim de pôr em evidência experiências, pesquisas, fatos, dados marcantes e emoções, os quais não tínhamos percebido e que podem ser fundamentais para se compreender o processo didático em suas várias dimensões: ensinar, aprender, pesquisar e avaliar. (Veiga, 2013, p. 50)

O mapa conceitual constitui-se de uma técnica de ensino, aprendizagem, pesquisa e avaliação que contribui para a aprendizagem, podendo ser utilizada nas diferentes etapas e modalidades de ensino.

De acordo com os participantes, o processo de elaboração, apresentação e produção de síntese do mapa conceitual possibilitou uma nova concepção de avaliação do processo de ensinoaprendizagem, constituindo-se uma ferramenta que permite estabelecer uma relação mais sistematizada entre o conteúdo apresentado com os conhecimentos anteriormente apreendidos.

4ª Atividade a distância: plano de ensino: A proposta era a elaboração do plano de ensino da disciplina que o professor vai ministrar no próximo semestre, considerando os estudos feitos sobre planejamento escolar na $2^{2}$ atividade a distância e demais temas desenvolvidos nos encontros formativos. Os espaços de discussão e reflexão sobre a prática pedagógica dos participantes da pesquisa oportunizaram o seu desenvolvimento profissional em diferentes aspectos, como entender 
a importância do planejamento como organização de seu trabalho, bem como a reorganização dele, diante dos objetivos propostos de sua disciplina e de toda a sua ação docente.

A atividade de elaboração do plano de ensino visou a busca dessa reflexão acerca do compromisso assumido a partir da necessidade de transformar a realidade em que está inserido, utilizando-se do plano de ensino como meio a ser utilizados para essa transformação. Os planos de ensino elaborados pelos professores foram postados na plataforma Google Classroom - utilizada para as atividades a distância.

60 Encontro presencial: avaliação do processo de formação pedagógica: O encontro constituiuse da avaliação dos ciclos reflexivos e atividades a distância, que ocorreram ao longo do semestre. Nesse encontro, também, fez-se a apresentação dos planos de ensino, que foram elaborados como proposta na $4^{\mathrm{a}}$ atividade a distância.

Os participantes manifestaram a satisfação de terem participado dos encontros e das atividades a distância, assim como as dificuldades e limitações que tiveram no processo.

\section{Considerações}

Iniciamos e encerramos o processo de formação nos aportando em Ibiapina (2008), a qual afirma que o princípio da pesquisa colaborativa é investigar a própria prática para nela intervir e a relação entre o pensamento e ação docente torna-se mais clara na medida em que os participantes se tornam mais conscientes sobre sua prática e passam a ter uma visão crítica do que é o fazer educativo.

Considerando os resultados da pesquisa, podemos afirmar que a docência no ensino superior, tratando-se de engenheiros que assumiram essa atividade, requer diferentes saberes, e a pesquisa colaborativa, por meio das atividades presenciais e a distância, nos grupos de reflexões, pôde contribuir para a apreensão de saberes, analisados a partir dos núcleos de significação apreendidos pelos sujeitos inseridos em um coletivo. As ações formativas puderam auxiliar o professor a valorizar o pensamento do outro, propiciando ambientes de discussão, de autonomia e de respeito mútuo e os mesmos compreenderam que o desenvolvimento da reflexão é necessário, o que pode promover mudança em sua prática docente. O que podemos afirmar é que a pesquisa colaborativa propiciou a interação dos participantes, por meio do diálogo que subsidiou o exercício da práxis, tanto nos encontros formativos, como na docência, uma práxis na qual teoria e prática se complementam e podem transformar-se, produzindo conhecimentos que impliquem mudanças da ação educativa, compreendendo as contribuições para novos caminhos profissionais. 
REFERÊNCIAS

BARBOSA, Eduardo Fernandes; MOURA Dácio Guimarães de. Metodologias ativas de aprendizagem no ensino de engenharia. XIII International Conference on Engineering and Technology Education. Guimarães - Portugal, 2014.

CONSELHO NACIONAL DE EDUCAÇÃO (Brasil). Resolução CNE/CES no 02, de 24 de abril de 2019. Institui as Diretrizes Curriculares Nacionais do Curso de Graduação em Engenharia. Brasília, DF: CNE, 2019b. Disponível em: http://abmes.org.br/arquivos/legislacoes/ResolucaoCNE-CES-002-2019-04-24.pdf. Acesso em: 26 set. 2019.

DESGAGNÉ, Serge. O conceito de pesquisa colaborativa: a idéia de uma aproximação entre pesquisadores universitários e professores práticos. Educação em Questão, Natal, v. 29, n. 15, p. 7-35, maio/ago. 2007.

IBIAPINA, Ivana Maria Lopes de Melo. Pesquisa colaborativa: investigação, formação e produção de conhecimentos. Brasília, DF: Líber Livro Editora, 2008. v. 1.

IBIAPINA, Ivana Maria Lopes de Melo. Pesquisar e formar colaborativamente: desafios e perspectivas. In: BALDI, Elena Mabel; FERREIRA, Maria Salonilde; PAIVA, Marlúcia.

Epistemologia das ciências da educação. Edufrn, 2009.

IBIAPINA, Ivana Maria Lopes de Melo. Pesquisa colaborativa: multirreferenciais e práticas convergentes.1. ed. Teresina: Edufpi, 2016.

LIBÂNEO, José Carlos. Didática. São Paulo: Cortez, 1994.

MAGALHÃES, Maria Cecilia Camargo. Projetos de formação contínua de educadores para uma prática crítica. The ESPecialist, São Paulo, v. 19, n. 2, p. 169-184, 2009.

MOREIRA, Marcos Antônio. Mapas conceituais e aprendizagem significativa. São Paulo: Centauro Editora, 2010.

SANTOS, Juliana. Ormastroni de Carvalho. MAGALHÃES, Maria Cecília Camargo. Padrões de colaboração nas relações entre alunas e professora em sala de aula na discussão sobre o gênero "notícia". In: oo, Rio de Janeiro, v.14, n.40, p. 143-155, 2016.

VEIGA, Ilma Passos Alencastro.(org). Ensinar, Aprender, Pesquisar e Avaliar com Mapas Conceituais.In: Novas tramas para as técnicas de ensino e estudo. Campinas, SP: Papirus, 2013. 
VIGOTSKI, Lev Semenovich. Pensamento e linguagem. São Paulo: Editora Mart, 1998.

VITO, Daniela Ziolli; SZEZERBATZ, Rosimari Pedroso. A avaliação no ensino superior: a importância da diversificação dos instrumentos no processo avaliativo. EDUCERE - Revista da Educação, Umuarama, v. 17, n. 2, p. 221-236, jul./dez. 2017.

\title{
Continuing Teacher Training: a collaborative research with teachers- engineers
}

\begin{abstract}
This article presents part of a collaborative research entitled "Continuing education of teacher-engineers: a collaborative research", developed with professors from the engineering courses of the Institute of Technological and Exact Sciences (ICTE) of the Federal University of Triângulo Mineiro - UFTM, aiming to contribute to their professional development. The research was based on the qualitative approach, using Historical-Dialectic Materialism as a method. The section chosen for this article refers to the description of the collaborative research used because it expects knowledge to be built through the interaction of subjects - participants and researcher, seeking to reflect on the meanings of their own actions. Collaborative research, through face-to-face and distance activities, in reflection groups, could contribute to the apprehension of knowledge and could help the teacher to value the other's thinking, providing environments for discussion, autonomy and mutual respect and the they understood that the development of reflection is necessary, which can promote change in their teaching practice.
\end{abstract}

Keywords: Teacher training. Collaborative research. Teacher professional development. 